\title{
You can't fix what isn't broken: Eight weeks of exercise do not substantially change cognitive function and biochemical markers in young and healthy adults
}

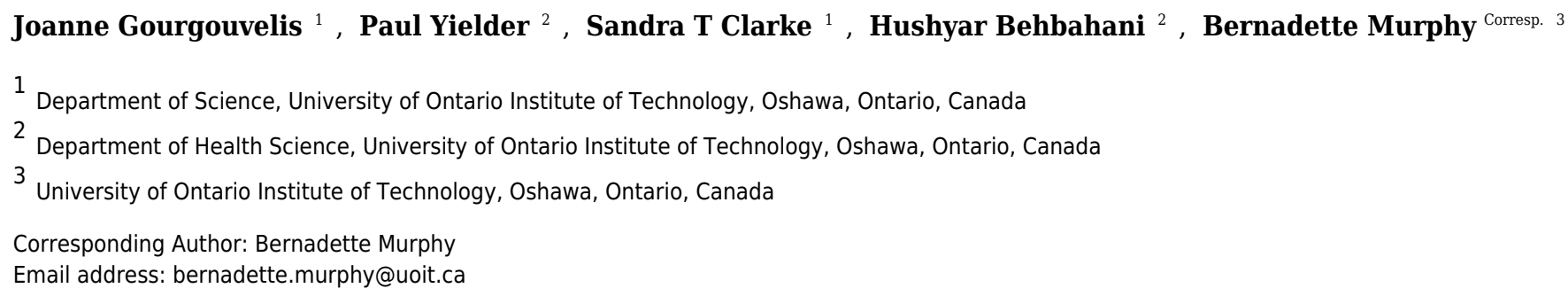

Objective: The benefits of exercise on brain health is well known in aging and psychiatric populations. However, the relationship between habitual exercise in young and healthy adults remains unclear. This study explored the effects an eight-week exercise prescription on cognitive function, brain-derived neurotrophic factor (BDNF) and cathepsin B (CTHB) in young and healthy adults.

Methods: Twenty-two low-active, young and healthy adults were recruited from a local university. Twelve participants performed an eight-week exercise prescription and twelve participants served as controls. Cognitive assessments, cardiorespiratory fitness and plasma BDNF and CTHB concentrations were measured at baseline and eight weeks.

Results: Results showed exercise improved cardiorespiratory fitness ( $p=0.044, d=1.48$ ) with no improvements in cognitive function or no changes in plasma BDNF and CTHB concentrations.

Conclusion: We provide evidence that a short term course of moderate exercise does not improve cognitive function or change plasma biochemical markers concentrations in young and healthy adults, despite mild improvements in cardiorespiratory fitness. These results suggest that cognitive health may peak during early adulthood leaving little room for improvement throughout this period of the lifespan. 
1 You can't fix what isn't broken: Eight weeks of exercise do not substantially

2 change cognitive function and biochemical markers in young and healthy

3 adults

4

5 Joanne Gourgouvelis ${ }^{1}$, Paul Yielder ${ }^{1}$, Sandra T Clarke ${ }^{1}$, Hushyar Behbahani ${ }^{1}$, Bernadette

6 Murphy $^{1}$

7 Affiliations:

8 1: University of Ontario Institute of Technology, Oshawa, Ontario, Canada

9

10

11

12

13

14

15

16

17 Corresponding Author:

18 Bernadette Murphy

19 University of Ontario Institute of Technology

202000 Simcoe Street North, Oshawa, Ontario, Canada. L1H 7K4

21 Email: Bernadette.murphy@uoit.ca

22 Phone: 905-550-4055 
24 You can't fix what isn't broken: Effects of eight weeks of exercise on cognitive function and biochemical markers in young and healthy adults

\section{ABSTRACT}

Objective

The benefits of exercise on brain health is well known in aging and psychiatric populations. However, the relationship between habitual exercise in young and healthy adults remains unclear. This study explored the effects an eight-week exercise prescription on cognitive function, brain-derived neurotrophic factor (BDNF) and cathepsin B (CTHB) in young and healthy adults.

\section{Methods}

Twenty-two low-active, young and healthy adults were recruited from a local university. Twelve participants performed an eight-week exercise prescription and twelve participants served as controls. Cognitive assessments, cardiorespiratory fitness and plasma BDNF and CTHB concentrations were measured at baseline and eight weeks.

\section{Results}

Results showed exercise improved cardiorespiratory fitness ( $p=0.044, d=1.48$ ) with no improvements in cognitive function or no changes in plasma BDNF and CTHB concentrations.

\section{Conclusion}

We provide evidence that a short-term course of moderate exercise does not improve cognitive function or change plasma biochemical markers concentrations in young and healthy adults, despite mild improvements in cardiorespiratory fitness. These results suggest that cognitive health may peak during early adulthood leaving little room for improvement throughout this period of the lifespan. 
INTRODUCTION

has exercise been shown to prevent disease, but exercise is considered an effective treatment for several medical conditions (Naci \& Ioannidis, 2013; Pedersen \& Saltin, 2006). More recently, considerable attention has focused on the positive effects of exercise on brain structure and function. In elderly populations, exercise has been shown to increase brain volume in selective areas such as the hippocampus and prefrontal cortex (Colcombe et al., 2006; Erickson et al., 55 2009; Erickson, Voss, Prakash, Basak, Szabo, Chaddock, Kim, Heo, Alves, White, et al., 2011). Additionally, exercise improves memory (Erickson, Voss, Prakash, Basak, Szabo, Chaddock,

57 Kim, Heo, Alves, \& White, 2011; Voss et al., 2013), executive function (Voss et al., 2010a), attention (Salthouse \& Davis, 2006) and decreases cognitive processing speed (Salthouse \& Davis, 2006). Exercise has also shown to be effective in treating mental health disorders such as anxiety (Herring, O’Connor, \& Dishman, 2010), depression (Blumenthal et al., 1999; Stathopoulou, Powers, Berry, Smits, \& Otto, 2006) and schizophrenia (Stathopoulou et al., 2006). Complementing human findings, the rodent literature has shown exercise to upregulate adult neurogenesis (van Praag, Kempermann, \& Gage, 1999), increase neuronal survival (Kobilo et al., 2011), enhance dendritic growth (Leggio et al., 2005), increase dendritic spine density (Eadie, Redila, \& Christie, 2005), enhance synaptic plasticity (Farmer et al., 2004), induce angiogenesis (Swain et al., 2003), enhance learning (Henriette van Praag, Shubert, Zhao, \&

67 Gage, 2005), and improve memory (Marlatt, Potter, Lucassen, \& van Praag, 2012). 
69

70

71

72

73

74

75

76

77

78

79

80

81

82

central nervous system. Although the precise mechanisms underlying the neurogenic effects of exercise remain unclear, a growing body of literature suggests that exercise activates

neurotrophic mechanisms known to promote neuroplasticity. Most notably, brain-derived neurotrophic factor (BDNF) is emerging as a key molecule underlying the benefits of exercise on brain function (Cotman, Berchtold, \& Christie, 2007). BDNF is an activity-dependent secreted protein essential for neural growth, neural survival (Barde, 1990) and synaptoplastic processes critical for learning and memory (Pang \& Lu, 2004; Yamada, Mizuno, \& Nabeshima, 2002). The brain contributes to approximately $70-80 \%$ of peripheral BDNF where it is stored and released from circulating platelets upon activation (Fujimura et al., 2002; Rasmussen et al., 2009; Yamamoto \& Gurney, 1990). BDNF is also produced in various peripheral tissues including skeletal muscle and adipose tissue and is able to cross the blood-brain barrier (Matthews et al., 2009; Pan, Banks, Fasold, Bluth, \& Kastin, 1998; Sornelli, Fiore, Chaldakov, \& Aloe, 2009). In rodents, exercise rapidly increases the BDNF gene expression in brain regions involved with learning and memory formation, particularly in the hippocampus (Berchtold, Chinn, Chou, Kesslak, \& Cotman, 2005; Cotman \& Berchtold, 2002; Cotman et al., 2007; Neeper, GómezPinilla, Choi, \& Cotman, 1995). Similar to the increases of central BDNF expression observed in rodents, research has consistently shown that acute exercise increases peripheral BDNF concentrations in humans (Ferris, Williams, \& Shen, 2007; Knaepen, Goekint, Heyman, \& Meeusen, 2010; Rojas Vega et al., 2006). However, the literature supporting elevations in resting peripheral BDNF concentrations following a long-term exercise intervention have been mixed. In older adults, a one year moderate intensity aerobic intervention significantly increased resting plasma and serum BDNF concentrations (Erickson, Voss, Prakash, Basak, Szabo, Chaddock, 
91 Kim, Heo, Alves, White, et al., 2011) that was positively associated with age (Leckie et al.,

92 2014). In patients with Major Depressive Disorder (MDD), an eight week moderate aerobic and

93 resistance intervention significantly increased plasma BDNF concentrations (Gourgouvelis,

94 Murphy, \& Yielder, 2017) while no change in serum BDNF concentrations were observed

95 following a three month aerobic exercise intervention (Krogh et al., 2014). In young and healthy

96 adults, a five week moderate aerobic intervention significantly increased resting plasma BDNF

97 concentrations (Zoladz et al., 2008) while no increase in plasma BDNF concentrations were

98 observed following 12 weeks of strength or 12 weeks of moderate endurance training (Schiffer,

99 Schulte, Hollmann, Bloch, \& Strüder, 2009) and no change in serum BDNF concentrations

100 following three weeks of moderate aerobic activity (Griffin et al., 2011). The lack of consistent

101 findings examining the effects of long-term exercise on BDNF might be attributed to the mode

102 of exercise, varying intensities and exercise durations between studies.

It was recently demonstrated that cathepsin B (CTHB), a cysteine proteinases produced

by contracting skeletal muscle, is capable of penetrating the blood-brain barrier and upregulating both BDNF expression and hippocampal neurogenesis in wild-type mice (Moon et al., 2016).

106 Following long-term running, researchers also observed an increase in plasma CTHB

107 concentrations that was associated with improved memory performance in mice, Rhesus

108 monkeys and humans (Moon et al., 2016). several age associated neurodegenerative diseases and psychiatric disorders (Bocchio-Chiavetto

111 et al., 2010; Diniz \& Teixeira, 2011; Erickson \& Barnes, 2003). As such, research investigating

112 the exercise-cognition relationship has focused on these populations, with few studies examining 113 this relationship in young and healthy adults. The objectives of this study were to investigate the 
114 effects of a well characterized eight-week exercise intervention on cognitive function in low-

115 active, young and healthy adults. We targeted low-active individuals as they may show a greater

116 effect of a relatively short duration intervention. We also investigated whether changes in

117 cognitive function were linked to changes in plasma BDNF and CTHB concentrations.

\section{METHODS}

\section{Participants}

120 Twenty-two university students (mean age $=21.10, S D=1.27 ; 12$ females) were recruited from a

121 local university in Oshawa, Ontario Canada. All participants completed the Physical Activity

122 Readiness Questionnaire (PAR-Q) to screen for contraindications to exercise. Inclusion criteria

123 included: male or female age 18-30, no history of mental health illness, low-active (exercise less

124 than 20 minutes, three times weekly) and low cardiorespiratory fitness based on the Canadian

125 Society for Exercise Physiology guidelines (Canadian Society for Exercise Physiology, 1998).

126 Participants were then randomly assigned to an exercise intervention group or a control group to

127 provide baseline and post assessment comparisons. All measures were performed at baseline and

128 then again following the eight-week intervention (see Figure 1 for the experiment timeline).

129 Participants were instructed not to engage in physical activity the day of testing. This study was 130 approved by the Ontario Institute of Technology Research Ethics Board \#11979 - (10-104). All 131 participants provided written consent.

132 Neuropsychological measures

133 Cambridge Neuropsychological Test Automated Battery (CANTAB)

134 Cognitive performance was evaluated using the Cambridge Neuropsychological Test Automated 135 Battery (CANTAB) software (Cambridge Cognition, Cambridge, UK;

136 http://www.cambridgecognition.com/cantab/cognitive-tests/). CANTAB is currently the most 
137 widely published automated neuropsychological test battery (Wild, Howieson, Webbe, Seelye, \&

138 Kaye, 2008) possessing high levels of concurrent validity and test-retest reliability (Fowler,

139 Saling, Conway, Semple, \& Louis, 1995). CANTAB is an accurate, faster and more efficient

140 method to assess cognitive functioning than traditional pen and paper tools (Fray \& Robbins,

141 1996). All tests use non-verbalisable patterns and are presented on a computer touch screen in a

142 game-like format that provides immediate feedback to reduce boredom (Levaux et al., 2007).

143 The CANTAB tests included in our assessment battery assess executive function, learning and

144 memory which have previously shown to improve following an exercise intervention (Stanley J

145 Colcombe et al., 2004; Kirk I Erickson, Voss, Prakash, Basak, Szabo, Chaddock, Kim, Heo,

146 Alves, White, et al., 2011; Ruscheweyh et al., 2011; Voss et al., 2010b) and to be sensitive to

147 changes in the hippocampus and frontal lobes (de Rover et al., 2011; Owen, Roberts, Polkey,

148 Sahakian, \& Robbins, 1991; Winocur, Wojtowicz, Sekeres, Snyder, \& Wang, 2006). A brief

149 description of each test included in this study is provided below.

150

151

152

153

154

155

156

157

158

159

Delayed Matching to Sample (DMS): This test assesses recognition memory for patterns. The subject is shown a complex visual pattern and then must choose one of four similar patterns that matches the original pattern. In some trials the sample and the choice patterns are shown simultaneously, while in others there is a delay of 0,4 or 12 seconds before the choices appear. Outcome measures included accuracy and correct response latency.

The Paired Associates Learning (PAL): This test assesses visual memory and new learning and is sensitive to changes in the temporal and frontal lobes. In this test, boxes are displayed on the screen and are opened in a randomized order with one or more containing a pattern. Each pattern is then displayed one at a time in the middle of the screen and the participant must identify the box where the pattern was located. The participant proceeds to the next stage when 
160 all the correct locations are identified. The test has an increasing level of difficulty that ranges

161 from two to eight patterns to be remembered. The total number of errors was used as the

162 outcome measure for this test.

163 The Spatial Recognition Memory (SRM): This test is a measure of visual spatial recognition

164 that uses a forced-choice discrimination paradigm in which participants must choose between

165 previously learned and novel stimuli. The percentage of total responses correct was used as the 166 outcome measure.

167 The Intra-Extra Dimensional Set Shift (IED): This test is a measure of rule acquisition and

168 reversal. This test assesses visual discrimination and attentional set formation, as well as

169 maintenance, shifting, and flexibility of attention. The number of stages completed and total

170 number of errors were used as the outcome measures.

171 Plasma collection

172 Blood samples were collected from each participant at baseline and eight weeks by venipuncture

173 into ethylenediaminetetraacetic acid tubes and centrifuged within 30 minutes. Fibrinogen

174 containing plasma supernatant was aliquotted and stored at $-85^{\circ} \mathrm{C}$ until analysis. Plasma BDNF

175 and total CTHB were quantified using enzyme-linked immunosorbant assays (ELISA) following

176 manufacturer's protocols (R\&D Systems, MN, USA; BioLegend, CA, USA). ELISA plates were

177 read at a wavelength of 450nm using a Synergy HTTR microplate reader (Bio-Tek

178 Instrumentation, VT, USA).

179 Fitness assessment 
180 In order to assess baseline fitness levels to determine eligibility and starting intensity for the

181 exercise intervention baseline cardiovascular fitness was assessed with the YMCA cycle

182 ergometer protocol recommended by the American College of Sports Medicine (Beekley,

183 Brechue, \& Dehoyos, 2004; Golding, Myers, \& Sinning, 1989; Pescatello \& American College

184 of Sports Medicine., 2014). This protocol is a submaximal exercise that estimates maximal

185 oxygen consumption $\left(\mathrm{VO}_{2} \mathrm{max}\right)$ from heart rate $(\mathrm{HR})$ measurements and perceived exertion. The

186 protocol consisted of two or more consecutive 3-minute stages at a given workload. The

187 objective was to elevate the participant's HR to a target zone between 110 beats per minute and 188 approximately $85 \%$ of the age-predicted maximum heart rate for two consecutive stages. The

189 initial workload consisted of a 25 Watt workload at a cadence of 50 revolutions per minute. The

190 workload of the subsequent stages increased by the amount specified by the YMCA protocol

191 based on the average HR during the last 2 min of each stage. When the target HR was achieved

192 for two consecutive stages, the test was considered complete. Participants were also assessed at 193 eight weeks to determine changes in cardiorespiratory fitness.

194 Exercise prescription

195 The exercise prescription was based on international guidelines of a minimum of 150 minutes

196 per week of moderate to vigorous intensity aerobic exercise in combination with resistance

197 activities two times per week, for developing and maintaining cardiorespiratory,

198 musculoskeletal, and neuromotor fitness in healthy adults (Canadian Society for Exercise

199 Physiology, 1998; Garber et al., 2011). All exercise sessions were supervised by a qualified

200 exercise professional. The exercise group performed one aerobic only and two resistance

201 sessions per week on non-consecutive days for a duration of eight weeks. The exercise intensity

202 for aerobic and resistance sessions were individualized based on each participant's target HR that 
203 ranged between $60-80 \%$ of their age-predicted maximum HR. Radial pulse was frequently

204 measured throughout each aerobic and resistance exercise session to confirm that participants

205 maintained their target HR range.

206 Aerobic session

207 Participants were given the opportunity to choose their aerobic activity on either the treadmill,

208 stationary bike or elliptical machine. Aerobic workloads were based on HR response and were

209 increased by five-minute increments, over the eight weeks, reaching a maximum of 60 minutes

210 per session.

\section{Resistance sessions}

212 Resistance sessions combined a whole-body exercise prescription engaging the larger muscle

213 groups. For each session, participants performed eight resistance exercises using free weights

214 and resistance training machines. Exercises were performed consecutively in two or three

215 supersets (with an 8-12 repetition range) to minimize rest times and to maintain target HR range.

216 Initial workloads were individualized for each participant based on approximately $95 \%$ of their

21710 repetition maximum. Subsequent workloads were increased approximately 5\% once

218 participants were able to complete three sets of 12 repetitions. Exercises were changed every

219 four weeks to avoid adaptation; although still targeting the same muscle groups. Each session

220 incorporated a 5 minute aerobic warmup and concluded with a 15 minute aerobic activity.

(INSERT FIGURE 1) 


\section{Statistical analysis}

225 All data were analyzed using Prism GraphPad software, version 6.0. Continuous data are

226 presented as means and standard deviation (SD) and categorical data are presented as

227 frequencies. Independent samples $t$-tests were used to compare baseline variables across groups

228 for continuous variables and Fisher's exact tests were used to compare categorical variables.

229 Paired $t$-tests were used to determine within-group changes from pre-post testing. A two-way

230 analysis of variance (ANOVA) with repeated measures (Group by Time) was used to determine

231 pre-post changes and between-group differences. Statistical significance was set at $p<0.05$ (two-

232 tailed) and all p-values were Bonferroni corrected. A modified version of Cohen's D $\left(d_{p p c 2}\right)$

233 specifically designed for pre-post experiments to account for any differences at baseline was

234 used to calculate effects sizes (Morris, 2007).

\section{RESULTS}

\section{Baseline characteristics between groups}

237 Baseline group analyses revealed no significant differences for sex, age, BMI, BDNF and CTHB

238 (see Table 1). One $(n=1)$ participant from the control group discontinued $\mathrm{VO}_{2}$ max testing due to

239 exhaustion and was excluded from the $\mathrm{VO}_{2}$ max analysis. The control group showed a

240 significantly higher mean $\mathrm{VO}_{2}$ max than the exercise group, $t(19)=3.29, p=.004$, however all

241 participants met the Poor Health Benefit Rating Zone for cardiorespiratory fitness criteria based

242 on the Canadian Society for Exercise Physiology guidelines (Canadian Society for Exercise

243 Physiology, 1998).

244 Pre-post measures

245 A two-way ANOVA with repeated measures revealed a group by time interaction for $\mathrm{VO}_{2}$ max, $f$

$246(1,19)=7.90, p=.044 ; d=1.48$, indicating that the exercise intervention was able to improve 
247 cardiorespiratory fitness. Biochemical marker analysis revealed no significant group-by-time

248 effects for BDNF, $f(1,20)=1.29, p=.296 ; d=.39$, or CTHB, $f(1,19)=.812, p=.379 ; d=.253$, see

249 Figure 2. Although the cognitive analyses from the CANTAB battery revealed no significant 250 group-by-time effects for the DMS, PAL, SRM or IED (see Figure 3), a paired $t$-test revealed

251 that the exercise group performed significantly better on the PAL task post intervention

$252 t(11)=3.30, p=.042 ; d=1.35$. All pre-post results are shown in Table 2 .

253

254 (INSERT TABLE 1)

255 (INSERT FIGURE 2)

256 (INSERT FIGURE 3)

257 (INSERT TABLE 2)

258

259

\section{DISCUSSION}

This present study demonstrated that an eight-week exercise intervention, based on the minimum recommended guidelines, was able to significantly improve cardiorespiratory fitness in low-active, young and healthy adults. We provide evidence that exercise did not significantly improve cognitive function or change resting plasma BDNF or CTHB concentrations, despite improvements in fitness. Our findings suggest that if biomarker levels are within normal ranges at baseline, then exercise does not change these ranges in young and healthy adults. Cognitive function peaks during this time and thus to show effects of exercise on brain function may require more sensitive tests than provided by standardize cognitive testing batteries. performance, the exercise group showed improved accuracy for the PAL task. Although our 
270 findings agree with previous research (Etnier, Nowell, Landers, \& Sibley, 2006; Felez-Nobrega,

271 Hillman, Cirera, \& Puig-Ribera, 2017; Kamijo, O’leary, Pontifex, Themanson, \& Hillman, 2010;

272 Themanson, Pontifex, \& Hillman, 2008), there has been evidence that regular exercise may have

273 cognitive benefits for young adults (Aberg et al., 2009; Guiney \& Machado, 2013; Themanson et

274 al., 2008). The inconsistent behavioural findings in the exercise-cognition literature in young

275 adults may be attributed to using cognitive performance measures not sensitive enough to detect

276 small changes in cognitively high-functioning young adults. Whereas the benefits of exercise on

277 cognitive performance observed in elderly adults may be attributed to the potentially greater gains

278 where an age-related decline of cognitive functioning has occurred.

279 In an attempt to link a physiological mechanism underlying the effects of exercise on

280 cognitive function, we measured plasma BDNF and CTHB concentrations. We did not observe

281 any change in plasma BDNF concentrations following the exercise intervention agreeing with

282 previous research conducted in young and healthy adults (Griffin et al., 2011; Schiffer et al.,

283 2009). Though our study did not replicate Moon et al., who observed an increase in plasma

284 CTHB following four months of aerobic exercise, our intervention was much shorter in duration.

285 It is worth noting that the animal literature has reported reduced CTHB gene expression in the

286 cardiac muscle of mice following five days of treadmill running (Smuder, Kavazis, Min, \&

287 Powers, 2013) and no change in CTHB activity in skeletal muscle following eight hours of

288 exhaustive exercise (Salminen, 1984). However, little is known about the role that CTHB plays

289 in cognitive function in humans.

\section{LIMITATIONS}

291 This study was limited by the small sample size. Second, while our eight-week exercise

292 intervention was able to significantly increase in cardiorespiratory fitness in young and healthy 
293 adults who were low-active, all participants in the exercise group remained in the poor fitness

294 category following the intervention. As such, significant improvements in cognitive function

295 may have been observed with an intervention of longer duration featuring additional training

296 sessions. Future research should investigate the dose-response effects of exercise on

297 cardiorespiratory fitness, cognitive function and biomarkers by comparing various durations of

298 exercise. Furthermore, the CANTAB battery used for this study might not have been sensitive

299 enough to detect changes in this high-functioning group of young and healthy adults. It is

300 possible that the effects of exercise on cognitive behavior may only emerge when the task is

301 extremely difficult (Voss, Nagamatsu, Liu-Ambrose, \& Kramer, 2011).

\section{CONCLUSION}

303 This study provides evidence that eight weeks of the minimum recommended dose of exercise

304 does not change cognitive function, BDNF or CTHB concentrations in young and healthy, low-

305 active adults. Our sample is representative of the a $95 \%$ of the adult population in the United

306 States and Canada who do not meet the recommended physical activity guidelines for health

307 benefits (Colley et al., 2011; Troiano et al., 2008). In order to understand the magnitude of the

308 effects of exercise on cognitive function, and the relationship between cardiorespiratory fitness

309 and cognitive function across the life span, it is critical that we understand the impact of exercise

310 on cognitive function in young and healthy populations that are physically active and inactive.

\section{Acknowledgments}

312 The authors would like to thank Joanne Free and Julia Green-Johnson from the University of

313 Ontario of Technology, for their assistance, technical expertise and guidance. 
317

318

319

320

321

322

323

324

325

326

327

328

329

330

331

332

333

334

335

336

337

338

339

340

341

342

343

344

345

346

347

348

349

350

351

352

353

354

355

356

357

358

359

360

Aberg, M. A. I., Pedersen, N. L., Torén, K., Svartengren, M., Bäckstrand, B., Johnsson, T., ... Kuhn, H. G. (2009). Cardiovascular fitness is associated with cognition in young adulthood. Proceedings of the National Academy of Sciences of the United States of America, 106(49), 20906-11. https://doi.org/10.1073/pnas.0905307106

Barde, Y. A. (1990). The nerve growth factor family. Progress in Growth Factor Research, 2(4), 237-48. https://doi.org/10.1016/0955-2235(90)90021-B

Beekley, M., Brechue, W., \& Dehoyos, D. (2004). Cross-validation of the YMCA submaximal cycle ergometer test to predict VO2max. Quarterly for Exercise .... Retrieved from http://www.tandfonline.com/doi/abs/10.1080/02701367.2004.10609165

Berchtold, N. C., Chinn, G., Chou, M., Kesslak, J. P., \& Cotman, C. W. (2005). Exercise primes a molecular memory for brain-derived neurotrophic factor protein induction in the rat hippocampus. Neuroscience, 133(3), 853-861. https://doi.org/10.1016/j.neuroscience.2005.03.026

Blumenthal, J. a, Babyak, M. a, Moore, K. a, Craighead, W. E., Herman, S., Khatri, P., ... Krishnan, K. R. (1999). Effects of exercise training on older patients with major depression. Archives of Internal Medicine, 159(19), 2349-2356. https://doi.org/10.1001/archinte.159.19.2349

Bocchio-Chiavetto, L., Bagnardi, V., Zanardini, R., Molteni, R., Gabriela Nielsen, M., Placentino, A., ... Riva, M. A. (2010). Serum and plasma BDNF levels in major depression: a replication study and meta-analyses. World Journal of Biological Psychiatry, 11(6), 763773.

Canadian Society for Exercise Physiology. (1998). Canada's Physical Activity Guide to Healthy Active Living. Public Health Agency of Canada. Retrieved from http://publications.gc.ca/site/eng/9.646864/publication.html

Colcombe, S. J., Erickson, K. I., Scalf, P. E., Kim, J. S., Prakash, R., McAuley, E., ... Kramer, A. F. (2006). Aerobic exercise training increases brain volume in aging humans. The Journals of Gerontology Series A: Biological Sciences and Medical Sciences, 61(11), 1166.

Colcombe, S. J., Kramer, A. F., Erickson, K. I., Scalf, P., McAuley, E., Cohen, N. J., ... Elavsky, S. (2004). Cardiovascular fitness, cortical plasticity, and aging. Proceedings of the National Academy of Sciences of the United States of America, 101(9), 3316-21. https://doi.org/10.1073/pnas.0400266101

Colley, R. C., Garriguet, D., Janssen, I., Craig, C. L., Clarke, J., \& Tremblay, M. S. (2011). Physical activity of Canadian adults: Accelerometer results from the 2007 to 2009 Canadian Health Measures Survey. Statistics Canada, 22(1). Retrieved from https://www.researchgate.net/profile/Ian_Janssen/publication/284685407_Physical_activity _of_Canadian_adults_accelerometer_results_from_the_2007_to_2009_Canadian_Health_M easures_Survey_Health_ReportsStatistics_Canada_Canadian_Centre_For_Health_Informati onRapports_Sur_La_S/links/568bb7ba08ae-1e63flfdd639.pdf

Cotman, C. W., \& Berchtold, N. C. (2002). Exercise: a behavioral intervention to enhance brain health and plasticity. Trends in Neurosciences, 25(6), 295-301. https://doi.org/10.1016/S0166-2236(02)02143-4

Cotman, C. W., Berchtold, N. C., \& Christie, L. (2007). Exercise builds brain health: key roles of growth factor cascades and inflammation. Trends in Neurosciences, 30(9), 464-472.

de Rover, M., Pironti, V. A., McCabe, J. A., Acosta-Cabronero, J., Arana, F. S., Morein-Zamir, 
402

403

404

405

406

S., ... Sahakian, B. J. (2011). Hippocampal dysfunction in patients with mild cognitive impairment: A functional neuroimaging study of a visuospatial paired associates learning task. Neuropsychologia, 49(7), 2060-2070. https://doi.org/10.1016/j.neuropsychologia.2011.03.037

Diniz, B. S., \& Teixeira, A. L. (2011). Brain-Derived Neurotrophic Factor and Alzheimer's Disease: Physiopathology and Beyond. NeuroMolecular Medicine, 13(4), 217-222. https://doi.org/10.1007/s12017-011-8154-X

Eadie, B. D., Redila, V. A., \& Christie, B. R. (2005). Voluntary exercise alters the cytoarchitecture of the adult dentate gyrus by increasing cellular proliferation, dendritic complexity, and spine density. The Journal of Comparative Neurology, 486(1), 39-47. https://doi.org/10.1002/cne.20493

Erickson, C. A., \& Barnes, C. A. (2003). The neurobiology of memory changes in normal aging. Experimental Gerontology, 38(1-2), 61-9. https://doi.org/10.1016/S0531-5565(02)00160-2

Erickson, K. I., Prakash, R. S., Voss, M. W., Chaddock, L., Hu, L., Morris, K. S., ... Kramer, A. F. (2009). Aerobic fitness is associated with hippocampal volume in elderly humans. Hippocampus, 19(10), 1030-1039.

Erickson, K. I., Voss, M. W., Prakash, R. S., Basak, C., Szabo, A., Chaddock, L., ... Kramer, A. F. (2011). Exercise training increases size of hippocampus and improves memory. Proceedings of the National Academy of Sciences of the United States of America, 108(7), 3017-22. https://doi.org/10.1073/pnas.1015950108

Erickson, K. I., Voss, M. W., Prakash, R. S., Basak, C., Szabo, A., Chaddock, L., ... White, S. M. (2011). Exercise training increases size of hippocampus and improves memory. Proceedings of the National Academy of Sciences, 108(7), 3017-3022.

Etnier, J. L., Nowell, P. M., Landers, D. M., \& Sibley, B. A. (2006). A meta-regression to examine the relationship between aerobic fitness and cognitive performance. Brain Research Reviews, 52(1), 119-30. https://doi.org/10.1016/j.brainresrev.2006.01.002

Farmer, J., Zhao, X., van Praag, H., Wodtke, K., Gage, F. ., \& Christie, B. . (2004). Effects of voluntary exercise on synaptic plasticity and gene expression in the dentate gyrus of adult male sprague-dawley rats in vivo. Neuroscience, 124(1), 71-79. https://doi.org/10.1016/j.neuroscience.2003.09.029

Felez-Nobrega, M., Hillman, C. H., Cirera, E., \& Puig-Ribera, A. (2017). The association of context-specific sitting time and physical activity intensity to working memory capacity and academic achievement in young adults. European Journal of Public Health, 27(4), 741746. https://doi.org/10.1093/eurpub/ckx021

Ferris, L. T., Williams, J. S., \& Shen, C.-L. (2007). The Effect of Acute Exercise on Serum Brain-Derived Neurotrophic Factor Levels and Cognitive Function. Psychobiology and Behavioral Strategies, 39(4), 728-734. https://doi.org/10.1249/mss.0b013e31802f04c7

Fowler, K. S., Saling, M. M., Conway, E. L., Semple, J. M., \& Louis, W. J. (1995). Computerized delayed matching to sample and paired associate performance in the early detection of dementia. Applied Neuropsychology, 2(2), 72-78. https://doi.org/10.1207/s15324826an0202_4

Fray, P. J., \& Robbins, T. W. (1996). CANTAB battery: proposed utility in neurotoxicology. Neurotoxicology and Teratology, 18(4), 499-504.

Fujimura, H., Altar, C. A., Chen, R., Nakamura, T., Nakahashi, T., Kambayashi, J., ... Tandon, N. N. (2002). Brain-derived neurotrophic factor is stored in human platelets and released by agonist stimulation. Thrombosis and Haemostasis, 87(4), 728-34. Retrieved from 
407

408

409

410

411

412

413

414

415

416

417

418

419

420

421

422

423

424

425

426

427

428

429

430

431

432

433

434

435

436

437

438

439

440

441

442

443

444

445

446

447

448

449

450

451

452

http://www.ncbi.nlm.nih.gov/pubmed/12008958

Garber, C. E., Blissmer, B., Deschenes, M. R., Franklin, B. A., Lamonte, M. J., Lee, I.-M., ... American College of Sports Medicine. (2011). American College of Sports Medicine position stand. Quantity and quality of exercise for developing and maintaining cardiorespiratory, musculoskeletal, and neuromotor fitness in apparently healthy adults: guidance for prescribing exercise. Medicine and Science in Sports and Exercise, 43(7), 1334-59. https://doi.org/10.1249/MSS.0b013e318213fefb

Golding, L. A., Myers, C. R., \& Sinning, W. E. (1989). Y's way to physical fitness : the complete guide to fitness testing and instruction. Published for YMCA of the USA by Human Kinetics Publishers.

Gourgouvelis, J., Murphy, B., \& Yielder, P. (2017). The Synergistic Effects Of Exercise In Combination With Other Antidepressant Therapies.: 1651 Board \#326 June 1 8. Medicine \&amp, 49(5S), 471. https://doi.org/10.1249/01.MSS.0000518181.45240.E1

Griffin, É. W., Mullally, S., Foley, C., Warmington, S. A., O’Mara, S. M., \& Kelly, Á. M. (2011). Aerobic exercise improves hippocampal function and increases BDNF in the serum of young adult males. Physiology \& Behavior, 104(5), 934-941.

https://doi.org/10.1016/j.physbeh.2011.06.005

Guiney, H., \& Machado, L. (2013). Benefits of regular aerobic exercise for executive functioning in healthy populations. Psychonomic Bulletin \& Review, 20(1), 73-86. https://doi.org/10.3758/s13423-012-0345-4

Herring, M. P., O’Connor, P. J., \& Dishman, R. K. (2010). The Effect of Exercise Training on Anxiety Symptoms Among Patients. Archives of Internal Medicine, 170(4), 321. https://doi.org/10.1001/archinternmed.2009.530

Kamijo, K., O’leary, K. C., Pontifex, M. B., Themanson, J. R., \& Hillman, C. H. (2010). The relation of aerobic fitness to neuroelectric indices of cognitive and motor task preparation. Psychophysiology, 47(5), 814-821. https://doi.org/10.1111/j.1469-8986.2010.00992.x

Knaepen, K., Goekint, M., Heyman, E. M., \& Meeusen, R. (2010). Neuroplasticity - exerciseinduced response of peripheral brain-derived neurotrophic factor: a systematic review of experimental studies in human subjects. Sports Medicine (Auckland, N.Z.), 40(9), 765-801. https://doi.org/10.2165/11534530-000000000-00000

Kobilo, T., Liu, Q.-R., Gandhi, K., Mughal, M., Shaham, Y., \& van Praag, H. (2011). Running is the neurogenic and neurotrophic stimulus in environmental enrichment. Learning \& Memory (Cold Spring Harbor, N.Y.), 18(9), 605-9. https://doi.org/10.1101/1m.2283011

Krogh, J., Rostrup, E., Thomsen, C., Elfving, B., Videbech, P., \& Nordentoft, M. (2014). The effect of exercise on hippocampal volume and neurotrophines in patients with major depression-A randomized clinical trial. Journal of Affective Disorders, 165, 24-30. https://doi.org/10.1016/j.jad.2014.04.041

Leckie, R. L., Oberlin, L. E., Voss, M. W., Prakash, R. S., Szabo-Reed, A., Chaddock-Heyman, L., ... Erickson, K. I. (2014). BDNF mediates improvements in executive function following a 1-year exercise intervention. Frontiers in Human Neuroscience, 8, 985. https://doi.org/10.3389/fnhum.2014.00985

Leggio, M. G., Mandolesi, L., Federico, F., Spirito, F., Ricci, B., Gelfo, F., \& Petrosini, L. (2005). Environmental enrichment promotes improved spatial abilities and enhanced dendritic growth in the rat. Behavioural Brain Research, 163(1), 78-90. https://doi.org/10.1016/j.bbr.2005.04.009

Levaux, M.-N., Potvin, S., Sepehry, A. A., Sablier, J., Mendrek, A., \& Stip, E. (2007). 
Computerized assessment of cognition in schizophrenia: promises and pitfalls of CANTAB. European Psychiatry, 22(2), 104-115.

Marlatt, M. W., Potter, M. C., Lucassen, P. J., \& van Praag, H. (2012). Running throughout middle-age improves memory function, hippocampal neurogenesis, and BDNF levels in female C57BL/6J mice. Developmental Neurobiology, 72(6), 943-952. https://doi.org/10.1002/dneu.22009

Matthews, V. B., Åström, M.-B., Chan, M. H. S., Bruce, C. R., Krabbe, K. S., Prelovsek, O., ... Febbraio, M. A. (2009). Brain-derived neurotrophic factor is produced by skeletal muscle cells in response to contraction and enhances fat oxidation via activation of AMP-activated protein kinase. Diabetologia, 52(7), 1409-1418. https://doi.org/10.1007/s00125-009-1364-1

Moon, H. Y., Becke, A., Berron, D., Becker, B., Sah, N., Benoni, G., ... van Praag, H. (2016). Running-Induced Systemic Cathepsin B Secretion Is Associated with Memory Function. Cell Metabolism (Vol. 24). https://doi.org/10.1016/j.cmet.2016.05.025

Morris, S. B. (2007). Estimating effect sizes from the pretest-posttest-control group designs. Organizational Research Methods.

Naci, H., \& Ioannidis, J. P. A. (2013). Comparative effectiveness of exercise and drug interventions on mortality outcomes: metaepidemiological study. BMJ, 347.

Neeper, S. A., Gómez-Pinilla, F., Choi, J., \& Cotman, C. (1995). Exercise and brain neurotrophins. Nature, 373(6510), 109. https://doi.org/10.1038/373109a0

Owen, A. M., Roberts, A. C., Polkey, C. E., Sahakian, B. J., \& Robbins, T. W. (1991). Extradimensional versus intra-dimensional set shifting performance following frontal lobe excisions, temporal lobe excisions or amygdalo-hippocampectomy in man. Neuropsychologia, 29(10), 993-1006. https://doi.org/10.1016/0028-3932(91)90063-E

Pan, W., Banks, W. A., Fasold, M. B., Bluth, J., \& Kastin, A. J. (1998). Transport of brainderived neurotrophic factor across the blood-brain barrier. Neuropharmacology, 37(12), 1553-1561. https://doi.org/10.1016/S0028-3908(98)00141-5

Pang, P. T., \& Lu, B. (2004). Regulation of late-phase LTP and long-term memory in normal and aging hippocampus: role of secreted proteins tPA and BDNF. Ageing Research Reviews, 3(4), 407-430. https://doi.org/10.1016/j.arr.2004.07.002

Pedersen, B. K., \& Saltin, B. (2006). Evidence for prescribing exercise as therapy in chronic disease. Scand J Med Sci Sports, 16((Suppl. 1)), 3-63.

Pescatello, L. S., \& American College of Sports Medicine. (2014). ACSM's guidelines for exercise testing and prescription (9th ed.). Philadelphia: Wolters Kluwer/Lippincott Williams \& Wilkins Health.

Rasmussen, P., Brassard, P., Adser, H., Pedersen, M. V., Leick, L., Hart, E., ... Pilegaard, H. (2009). Evidence for a release of brain-derived neurotrophic factor from the brain during exercise. Experimental Physiology, 94(10), 1062-1069. https://doi.org/10.1113/expphysiol.2009.048512

Rojas Vega, S., Strüder, H. K., Vera Wahrmann, B., Schmidt, A., Bloch, W., \& Hollmann, W. (2006). Acute BDNF and cortisol response to low intensity exercise and following ramp incremental exercise to exhaustion in humans. Brain Research, 1121(1), 59-65. https://doi.org/10.1016/j.brainres.2006.08.105

Ruscheweyh, R., Willemer, C., Krüger, K., Duning, T., Warnecke, T., Sommer, J., ... Flöel, A. (2011). Physical activity and memory functions: An interventional study. Neurobiology of Aging, 32(7), 1304-1319. https://doi.org/10.1016/j.neurobiolaging.2009.08.001

Salminen, A. (1984). Effects of the protease inhibitor leupeptin on proteolytic activities and 
regeneration of mouse skeletal muscles after exercise injuries. The American Journal of Pathology, 117(1), 64-70. Retrieved from http://www.ncbi.nlm.nih.gov/pubmed/6385726

Salthouse, T. A., \& Davis, H. P. (2006). Organization of cognitive abilities and neuropsychological variables across the lifespan. Developmental Review, 26(1), 31-54. https://doi.org/10.1016/j.dr.2005.09.001

Schiffer, T., Schulte, S., Hollmann, W., Bloch, W., \& Strüder, H. K. (2009). Effects of strength and endurance training on brain-derived neurotrophic factor and insulin-like growth factor 1 in humans. Hormone and Metabolic Research = Hormon- Und Stoffwechselforschung = Hormones et Metabolisme, 41(3), 250-4. https://doi.org/10.1055/s-0028-1093322

Smuder, A. J., Kavazis, A. N., Min, K., \& Powers, S. K. (2013). Doxorubicin-induced markers of myocardial autophagic signaling in sedentary and exercise trained animals. Journal of Applied Physiology (Bethesda, Md. : 1985), 115(2), 176-85. https://doi.org/10.1152/japplphysiol.00924.2012

Sornelli, F., Fiore, M., Chaldakov, G. N., \& Aloe, L. (2009). Adipose tissue-derived nerve growth factor and brain-derived neurotrophic factor: results from experimental stress and diabetes. General Physiology and Biophysics, 28 Spec No, 179-83. Retrieved from http://www.ncbi.nlm.nih.gov/pubmed/19893098

Stathopoulou, G., Powers, M. B., Berry, A. C., Smits, J. A. J., \& Otto, M. W. (2006). Exercise interventions for mental health: a quantitative and qualitative review. Clinical Psychology: Science and Practice, 13(2), 179-193.

Swain, R. A., Harris, A. B., Wiener, E. C., Dutka, M. V, Morris, H. D., Theien, B. E., ... Greenough, W. T. (2003). Prolonged exercise induces angiogenesis and increases cerebral blood volume in primary motor cortex of the rat. Neuroscience, 117(4), 1037-46. https://doi.org/10.1016/S0306-4522(02)00664-4

Themanson, J. R., Pontifex, M. B., \& Hillman, C. H. (2008). Fitness and action monitoring: Evidence for improved cognitive flexibility in young adults. Neuroscience, 157(2), 319328. https://doi.org/10.1016/J.NEUROSCIENCE.2008.09.014

Troiano, R. P., Berrigan, D., Dodd, K. W., M\&\#194, L. C., Tilert, T., \& Mcdowell, M. (2008). Physical Activity in the United States Measured by Accelerometer. Medicine \&amp, 40(1), 181-188. https://doi.org/10.1249/mss.0b013e31815a51b3

van Praag, H., Kempermann, G., \& Gage, F. H. (1999). Running increases cell proliferation and neurogenesis in the adult mouse dentate gyrus. Nature Neuroscience, 2(3), 266-270.

van Praag, H., Shubert, T., Zhao, C., \& Gage, F. H. (2005). Exercise Enhances Learning and Hippocampal Neurogenesis in Aged Mice. Journal of Neuroscience, 25(38). Retrieved from http://www.jneurosci.org/content/25/38/8680.short

Voss, M. W., Heo, S., Prakash, R. S., Erickson, K. I., Alves, H., Chaddock, L., ... Kramer, A. F. (2013). The influence of aerobic fitness on cerebral white matter integrity and cognitive function in older adults: results of a one-year exercise intervention. Human Brain Mapping, 34(11), 2972-85. https://doi.org/10.1002/hbm.22119

Voss, M. W., Nagamatsu, L. S., Liu-Ambrose, T., \& Kramer, A. F. (2011). Exercise, brain, and cognition across the life span. Journal of Applied Physiology, 111(5).

Voss, M. W., Prakash, R. S., Erickson, K. I., Basak, C., Chaddock, L., Kim, J. S., ... Kramer, A. F. (2010a). Plasticity of brain networks in a randomized intervention trial of exercise training in older adults. Frontiers in Aging Neuroscience, 2, 32. https://doi.org/10.3389/fnagi.2010.00032

Voss, M. W., Prakash, R. S., Erickson, K. I., Basak, C., Chaddock, L., Kim, J. S., ... Kramer, A. 
545 F. (2010b). Plasticity of brain networks in a randomized intervention trial of exercise $546 \quad$ training in older adults. Frontiers in Aging Neuroscience, 2, 32.

$547 \quad$ https://doi.org/10.3389/fnagi.2010.00032

548 Wild, K., Howieson, D., Webbe, F., Seelye, A., \& Kaye, J. (2008). Status of computerized

549 cognitive testing in aging: a systematic review. Alzheimer's \& Dementia, 4(6), 428-437.

550 Winocur, G., Wojtowicz, J. M., Sekeres, M., Snyder, J. S., \& Wang, S. (2006). Inhibition of

551 neurogenesis interferes with hippocampus-dependent memory function. Hippocampus,

552 16(3), 296-304.

553 Yamada, K., Mizuno, M., \& Nabeshima, T. (2002). Life sciences. Life Sciences (Vol. 7).

554 Pergamon. Retrieved from https:/www.infona.pl/resource/bwmetal.element.elsevier-

555 67e16bf6-a679-3673-8008-efb248d92879

556

557

558

Yamamoto, H., \& Gurney, M. E. (1990). Human platelets contain brain-derived neurotrophic factor. The Journal of Neuroscience: The Official Journal of the Society for Neuroscience, 10(11), 3469-78. Retrieved from http://www.ncbi.nlm.nih.gov/pubmed/2230938

Zoladz, J. A., Pilc, A., Majerczak, J., Grandys, M., Zapart-Bukowska, J., \& Duda, K. (2008). Endurance training increases plasma brain-derived neurotrophic factor concentration in young healthy men. Journal of Physiology and Pharmacology: An Official Journal of the Polish Physiological Society, 59 Suppl 7, 119-32. Retrieved from 


\section{Figure Captions}

567 Figure 1. Experimental timeline

568 Figure 2. Group plots illustrating pre-post biomarker changes for (A) plasma BDNF

569 concentrations, (B) plasma CTHB concentrations. Abbreviations: BDNF=brain-derived

570 neurotropic factor; $\mathrm{CTHB}=$ cathepsin $\mathrm{B}$

571 Figure 3. Group plots illustrating pre-post CANTAB changes for (A) DMS, (B) PAL, (C) SRM,

572 (D) IED. Abbreviations: DMS=delayed matching to sample; PAL=paired associates learning;

$573 \mathrm{SRM}=$ spatial recognition memory; $\mathrm{IED}=$ intra-extra dimensional set shift 


\title{
Figure 1 (on next page)
}

\author{
Experimental timeline
}




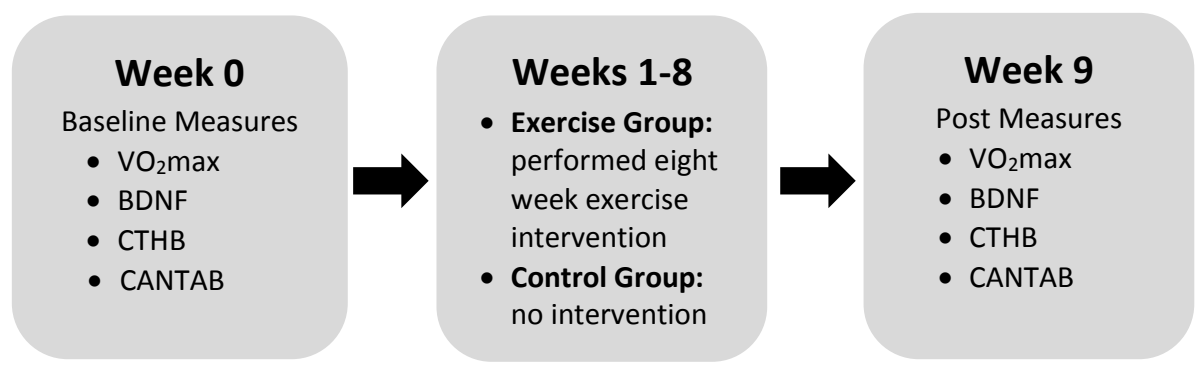


Figure 2 (on next page)

Group plots illustrating pre-post biomarker changes for (A) plasma BDNF concentrations, (B) plasma CTHB concentrations.

Abbreviations: $\mathrm{BDNF}=$ brain-derived neurotropic factor; $\mathrm{CTHB}=$ cathepsin $\mathrm{B}$. 
A.

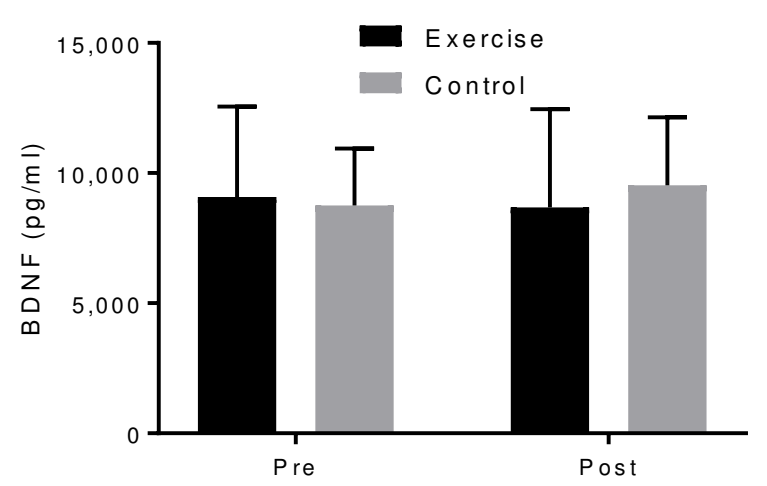

B.

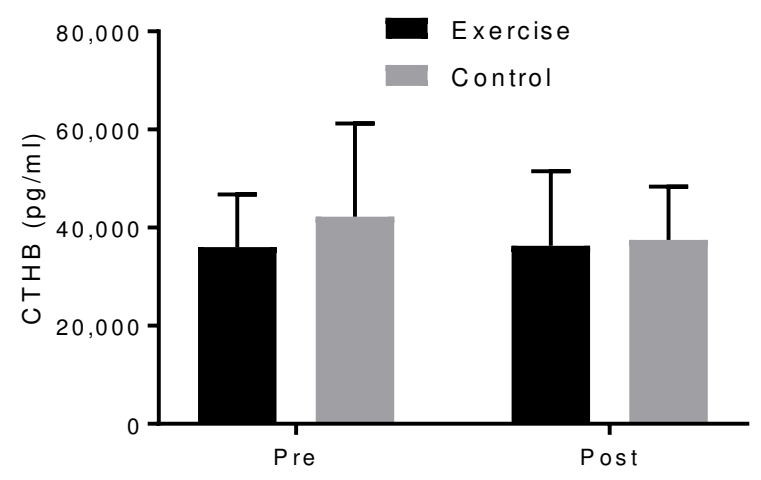




\section{Figure 3 (on next page)}

Group plots illustrating pre-post CANTAB changes for (A) DMS, (B) PAL, (C) SRM, (D) IED.

Abbreviations: $\mathrm{DMS}=$ delayed matching to sample; $\mathrm{PAL}=$ paired associates learning; $\mathrm{SRM}=$ spatial recognition memory; IED= intra-extra dimensional set shift. 
A.

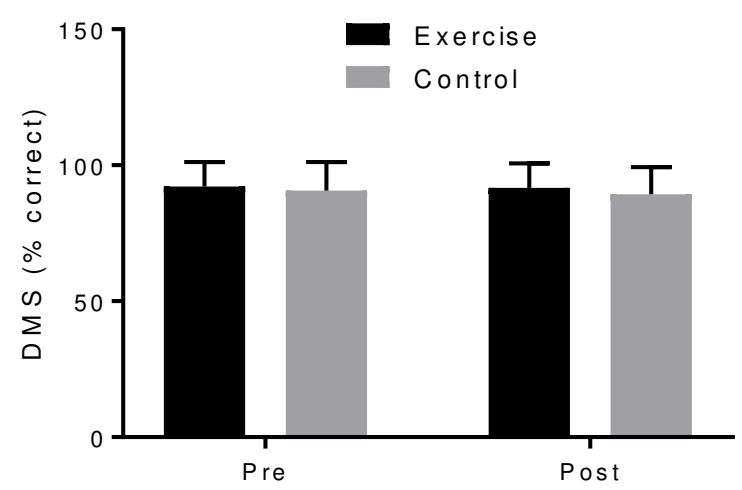

C.

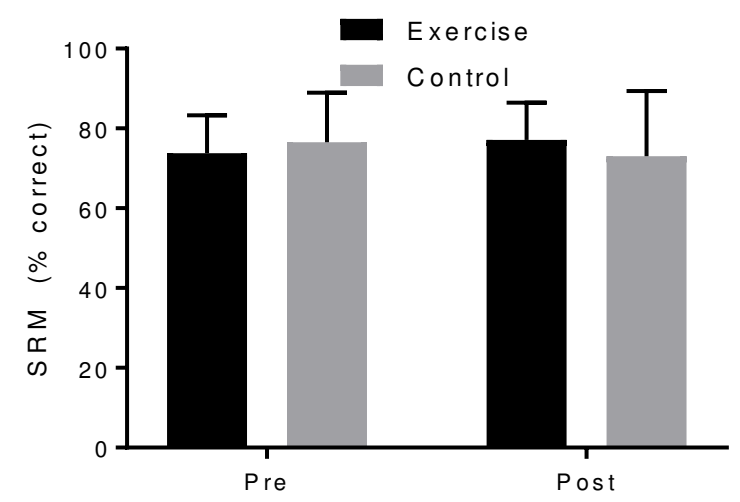

B.

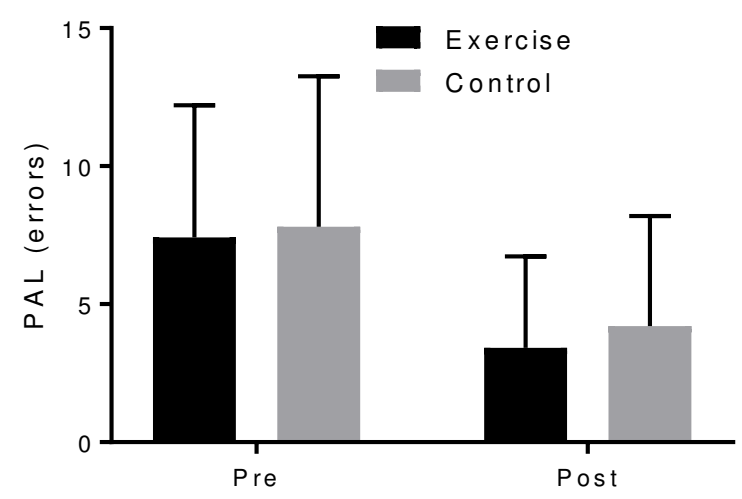

D.

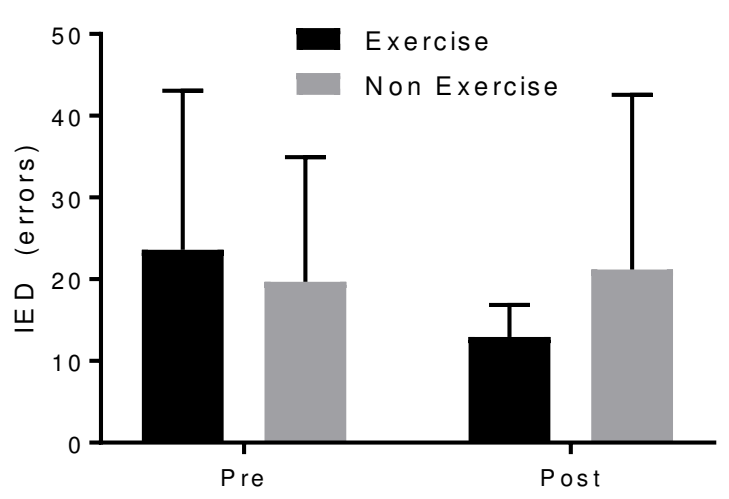




\section{Table $\mathbf{1}$ (on next page)}

Baseline characteristics of participants

a Pearson's chi-square

b Student's t-test

c One missing value

Abbreviation: $\mathrm{BMI}=$ body mass index; $\mathrm{VO}_{2} \max =$ maximum oxygen consumption

Data are expressed as the mean with the standard deviation in parentheses. 
2 Table 1

3 Baseline characteristics of participants

\begin{tabular}{lcccc}
\hline Variables & Exercise Group $(\mathrm{n}=12)$ & Controls $(\mathrm{n}=10)$ & $d f$ & $p$ \\
\hline Sex: $($ male/female) & $6 / 6$ & $4 / 6$ & 1 & $.639^{\mathrm{a}}$ \\
Age (years) & $21.08(1.24)$ & $21.16(1.30)$ & 20 & $.976^{\mathrm{b}}$ \\
$\mathrm{BMI}(\mathrm{kg} / \mathrm{m} 2)$ & $24.67(3.68)$ & $22.90(4.42)$ & 20 & $.319^{\mathrm{b}}$ \\
$\mathrm{VO}_{2} \mathrm{max}$ & $17.06(6.12)$ & $26.17(6.53)^{\mathrm{c}}$ & 20 & $\mathbf{. 0 0 4}^{\mathrm{b}}$ \\
$\mathrm{BDNF}(\mathrm{pg} / \mathrm{ml})$ & $9079(3480)$ & $8752(2198)$ & 20 & $.799^{\mathrm{b}}$ \\
CTHB $(\mathrm{pg} / \mathrm{ml})$ & $36,011(10,778)$ & $42,225(19,021)$ & 20 & $.354^{\mathrm{b}}$ \\
\hline
\end{tabular}

4 aPearson's chi-square

5 bStudent's t-test

$6{ }^{\mathrm{c}}$ One missing value

7 Abbreviation: $\mathrm{BMI}=$ body mass index; $\mathrm{VO}_{2} \max =$ maximum oxygen consumption

8 Data are expressed as the mean with the standard deviation in parentheses.

9 


\section{Table 2 (on next page)}

Results of pre-post changes for body mass index, fitness, BDNF, CTHB and CANTAB measures

Abbreviations: $\mathrm{SD}=$ standard deviation; $\mathrm{BMI}=$ body mass index; $\mathrm{VO}_{2}$ max $=$ maximal oxygen consumption; $\mathrm{BDNF}=$ brain derived neurotrophic factor; $\mathrm{CTHB}=$ cathepsin $\mathrm{B} ; \mathrm{CANTAB}=$ Cambridge Automated Test Automated Battery; DMS = delayed matching to sample; PAL = paired associate learning; $\mathrm{PRM}=$ pattern recognition memory; $\mathrm{SRM}=$ spatial recognition memory.

${ }^{a}$ One missing value

Data are expressed as mean with SD in parentheses. All p-values are Bonferroni corrected. 
Table 2

2 Results of pre-post changes for body mass index, fitness, BDNF, CTHB and CANTAB measures

\begin{tabular}{|c|c|c|c|c|c|c|c|c|c|c|c|c|c|}
\hline \multirow[b]{2}{*}{ Variables } & \multicolumn{5}{|c|}{ Exercise $(n=12)$} & \multicolumn{5}{|c|}{ Control $(\mathrm{n}=10)$} & \multicolumn{3}{|c|}{ Group Differences } \\
\hline & $\begin{array}{l}\text { Pre } \\
\text { mean (SD) }\end{array}$ & $\begin{array}{l}\text { Post } \\
\text { mean (SD) }\end{array}$ & $t$ & $p$ & $d$ & $\begin{array}{l}\text { Pre } \\
\text { mean (SD) }\end{array}$ & $\begin{array}{l}\text { Post } \\
\text { mean (SD) }\end{array}$ & $t$ & $p$ & $d$ & $F$ & $p$ & $d_{p p c 2}$ \\
\hline \multicolumn{14}{|l|}{ Biological } \\
\hline BMI (kg/m2) & $24.66(3.68)$ & $24.98(3.19)$ & .18 & .86 & .075 & $22.90(4.42)$ & $22.64(4.35)$ & .11 & .92 & .049 & .040 & .84 & .14 \\
\hline $\begin{array}{l}\mathrm{VO}_{2} \max \\
(\mathrm{mL} / \mathrm{kg} / \mathrm{min})\end{array}$ & $17.06(6.12)$ & $25.79(11.29)$ & 3.41 & .024 & 1.39 & $26.17(6.53)$ & $25.42(3.24)$ & .41 & $.70^{\mathrm{a}}$ & 0.19 & 7.90 & $.044^{\mathrm{a}}$ & 1.48 \\
\hline BDNF (pg/ml) & 9079 (3479) & $8680(3781)$ & .51 & .62 & .21 & $8751(2198)$ & $9528(2612)$ & 1.25 & .24 & .56 & 1.29 & .27 & .39 \\
\hline CTHB (pg/ml) & $36,011(10,778)$ & $36,332(15,178)$ & .079 & .939 & .024 & $40,972(18,366)$ & $37,526(10,826)^{\mathrm{a}}$ & 1.38 & .204 & .195 & .812 & .379 & .253 \\
\hline \multicolumn{14}{|l|}{ CANTAB } \\
\hline DMS (\% correct) & $92.22(8.91)$ & $91.67(9.04)$ & .14 & .89 & .057 & $90.67(10.52)$ & $89.33(10.04)$ & .41 & .69 & .18 & .022 & .89 & .081 \\
\hline $\begin{array}{l}\text { DMS response } \\
\text { latency }(\mathrm{ms})\end{array}$ & $3364(1057)$ & $3428(863.7)$ & .143 & .889 & .058 & $3660(730.3)$ & 3239 (494.6) & 1.91 & .089 & .85 & .838 & .37 & .52 \\
\hline PAL (total errors) & $7.42(4.80)$ & $3.42(3.32)$ & 3.30 & .042 & 1.35 & $7.80(5.453)$ & $4.20(3.99)$ & 1.94 & .085 & .87 & .035 & .85 & .077 \\
\hline SRM (\% correct) & $73.75(9.56)$ & $77.08(9.41)$ & 1.69 & .12 & .69 & $76.50(12.48)$ & $73.00(16.36)$ & .78 & .45 & .35 & 2.20 & .15 & .61 \\
\hline $\begin{array}{l}\text { SRM response } \\
\text { latency }(\mathrm{ms})\end{array}$ & $2588(833.3)$ & $2089(728.3)$ & 1.63 & .13 & .67 & $2805(1160)$ & 2234 (1397) & 1.29 & .23 & .58 & .019 & .89 & .071 \\
\hline IED (errors) & $23.58(19.50)^{\mathrm{a}}$ & $12.92(3.92)^{\mathrm{a}}$ & 1.75 & .108 & .66 & $19.70(15.24)$ & $21.20(21.35)$ & .335 & .745 & .15 & 2.41 & .136 & .68 \\
\hline
\end{tabular}

Abbreviations: $\mathrm{SD}=$ standard deviation; $\mathrm{BMI}=$ body mass index; $\mathrm{VO}_{2} \max =$ maximal oxygen consumption; $\mathrm{BDNF}=$ brain derived neurotrophic factor; $\mathrm{CTHB}=$ cathepsin $\mathrm{B} ; \mathrm{CANTAB}=\mathrm{Cambridge}$ Automated Test Automated Battery; DMS $=$ delayed matching to sample; $\mathrm{PAL}=$ paired associate learning; $\mathrm{PRM}=$ pattern recognition memory; $\mathrm{SRM}=$ spatial recognition memory

${ }^{a}$ One missing value

7 Data are expressed as mean with SD in parentheses.

8 All p-values are Bonferroni corrected 